\title{
Near-Death Encounters With and Without Near-Death Experiences: Comparative NDE Scale Profiles
}

\author{
Bruce Greyson, M.D. \\ University of Connecticut
}

\begin{abstract}
In a retrospective study contrasting the near-death encounters of 183 persons who reported near-death experiences and 63 persons who reported no near-death experience, the two groups did not differ in age, gender, or time elapsed since the near-death encounter. Near-death experiencers reported all 16 items of the NDE Scale significantly more often than did nonexperiencers.
\end{abstract}

Near-death experiences (NDEs), profound subjective events often experienced on the threshold of death, have received increased attention from scientists and clinicians in recent years (Lundahl, 1982; Greyson and Flynn, 1984; Rogo, 1989). While their frequent occurrence and their significance for the individual experiencer are no longer in question, controversy remains over the causes of these experiences and their ultimate meaning.

In order to establish reliable criteria for the occurrence and amplitude of NDEs, I developed a quantitative NDE Scale (Greyson, 1983). That 16-item scale can be used by researchers to explore the association between NDEs and hypothesized causal factors and aftereffects; and it can be used by clinicians to differentiate NDEs from other

Dr. Greyson is Associate Professor of Psychiatry at the University of Connecticut School of Medicine, and Director of the Inpatient Psychiatry Service at the John Dempsey Hospital. Requests for reprints should be addressed to Dr. Greyson at the Department of Psychiatry, University of Connecticut Health Center, Farmington, CT 06032. 
reactions to a near-death encounter, such as organic brain disorders and other stress responses. The NDE Scale has been shown to be both reliable and valid, and provides measures of "depth" of the NDE and of four components of the experience: Cognitive, Affective, Paranormal, and Transcendental (Greyson, 1983).

The NDE Scale is also useful in categorizing NDEs into discrete types (Greyson, 1985), based on whether the Cognitive, Affective, Paranormal, or Transcendental Component features are most prominent. Since different types of NDE may result from different mechanisms and may produce different aftereffects, they are worth distinguishing.

While the NDE Scale has been shown to be reliable, valid, and useful for clinical and research purposes, its specificity has never been established by studying the scores of individuals who do not report NDEs in a near-death encounter. The present study was undertaken to contrast the near-death encounters of persons who claimed to have had NDEs with those of persons who denied having had NDEs.

\section{Method}

\section{Subjects}

Subjects were recruited through advertisements in the newsletter of the International Association for Near-Death Studies, an organization founded to promote research into NDEs. Individuals responding to requests for subjects willing to complete questionnaires about their close brushes with death included 183 persons who claimed to have had NDEs (hereinafter called NDErs) and 63 persons who denied having had NDEs during their near-death encounters (hereinafter called nonNDErs).

\section{NDE Scale}

The 246 subjects in this study were mailed a modified version of the 16-item multiple-choice NDE Scale described elsewhere (Greyson, 1983), which quantifies the NDE and its Cognitive, Affective, Paranormal, and Transcendental Components (Greyson, 1985). The single modification was a rewording of the response alternatives for the first item, time distortion. 
In the original NDE Scale, possible responses to this question, "Did time seem to speed up?", included the following:

1. No.

2. Time seemed to go faster than usual.

3. Everything seemed to be happening all at once.

Subsequent experience with the NDE Scale suggested that the characteristic distortion in the sense of time in which more events than usual occur in a unit of subjective time might be described by some subjects as time seeming to go faster, and by other subjects as time seeming to go slower, depending on whether they interpreted "time" as the flow of events or as a constant against which those events are measured. Furthermore, many near-death experiencers (NDErs) find the question of time distortion unanswerable because they lost any sense of time during the experience. For these reasons, the possible responses to this question were expanded to read as follows:

1. No.

2. Time seemed to go faster than usual, or slower.

3. Everything seemed to be happening all at once; or time stopped, or lost all meaning.

With that one modification, the NDE Scale yielded a total score of 0-32 points $(0,1$, or 2 points for each of the 16 items). For research purposes, a score of 7 or higher (one standard deviation below the mean of 15) has been found to be an appropriate criterion for defining an NDE (Greyson, 1983).

Each of the four component subscales yielded a score of $0-8$ points $(0$, 1 , or 2 points for each of 4 items). The Cognitive Component was derived from items 1-4; the Affective Component, items 5-8; the Paranormal Component, items 9-12; and the Transcendental Component, items 13-16.

Cognitive NDEs were defined as those experiences that scored 5 or higher on the Cognitive Component, regardless of the scores on any other component. Transcendental NDEs were defined as those that scored 5 or higher on the Transcendental Component, but less than 5 on the Cognitive Component. Affective NDEs were defined as those that scored 5 or higher on the Affective Component, but less than 5 on either the Cognitive or Transcendental Component. Paranormal NDEs were defined as those that scored 5 or higher on the Paranormal Component, but less than 5 on any other component. 


\section{Statistical Analyses}

Gender ratios of the NDEr and nonNDEr groups were compared with the chi-squared test. Respondents' age at the time of the near-death event, and years elapsed since the near-death event, were compared between the two groups with Student's t test.

Mean scores of the NDEr and nonNDEr groups were compared on the total NDE Scale and on the four Component subscales with Student's t test. In addition, the comparative distribution of scores $(0,1$, or 2$)$ on each item was compared between the NDEr and nonNDEr groups with the chi-squared test.

Numbers of experiences reported by NDErs and nonNDErs that met criteria for research definitions of NDEs and of Cognitive, Affective, Paranormal, and Transcendental NDEs were compared with chisquared tests.

\section{Results}

Gender and Ages of NDErs and NonNDErs

Of the 183 NDErs, $69(38 \%)$ were male and $114(62 \%)$ female; of the 63 nonNDErs, $29(46 \%)$ were male and $34(54 \%)$ female. These gender ratios were not significantly different between the two groups (chisquared = 1.03; $\mathrm{df}=1$ ).

The mean age at the time of the near-death event was 32.5 years (S.D. $=15.3$ ) for NDErs and 30.5 years (S.D. $=16.7$ ) for nonNDErs. This age difference between the two groups was not significant $(\mathrm{t}=$ $0.89 ; \mathrm{df}=244$ ).

The mean length of time elapsed since the near-death event was 18.1 years (S.D. $=14.7)$ for NDErs and 22.3 years $($ S.D. $=16.4)$ for nonNDErs. This difference between the two groups in elapsed time since the near-death event was also not significant $(t=1.90 ; \mathrm{df}=244)$.

\section{NDE Scale Scores and NDE Component Scores of NDErs and nonNDErs}

The mean NDE Scale score of the 183 NDErs was $16.48($ S.D. $=6.96$ ), while that of the 63 nonNDErs was 3.79 (S.D. $=4.08$ ). This difference was significant at $\mathrm{p}<.0001(\mathrm{t}=13.7 ; \mathrm{df}=244)$. 
The NDE Scale also produced subscale scores for four discrete components of the NDE. The mean score for the Cognitive Component was 3.59 (S.D. $=2.18$ ) for NDErs and 1.13 (S.D. = 1.40) for nonNDErs; this difference was significant at $p<.0001(t=8.39 ; \mathrm{df}=244)$. The mean score for the Affective Component was 5.54 (S.D. = 2.46) for NDErs and 1.51 (S.D. $=2.04$ ) for nonNDErs; this difference was also significant at $\mathrm{p}<.0001(\mathrm{t}=11.70 ; \mathrm{df}=244)$.

The mean score for the Paranormal Component was 3.25 (S. D. = 2.02) for NDErs and 0.79 (S.D. = 1.17) for nonNDErs; this difference, like those above, was also significant at $p<.0001(t=9.16 ; \mathrm{df}=244)$. Finally, the mean score for the Transcendental Component was 4.11 (S.D. = 2.52) for NDErs and 0.37 (S.D. $=0.83$ ) for nonNDErs; this difference, like those for the other components, was significant at $\mathrm{p}<$ $.0001(\mathrm{t}=13.67 ; \mathrm{df}=244)$.

Although each of these four component scores yielded NDEr/ nonNDEr differences significant at the level of $p<.0001$, that value overestimates their significance, since the four components are not statistically independent. Using the Bonferroni procedure to correct for the interdependence of these four $t$ tests (Grove and Andreasen, 1982) yields a more accurate estimate of $p=.0004$ for the level of significance for each of these tests independently.

\section{NDE Scale Items Endorsed by NDErs and NonNDErs}

The 16 individual items that comprise the NDE Scale are listed in Table 1, along with the percent of NDErs and nonNDErs who endorsed each of the three alternative responses to each item, and chi-squared tests of the differences between the NDErs and the nonNDErs. Since tests on these 16 items are not statistically independent from each other, the Bonferroni correction was again used to estimate the significance of the calculated chi-squared values.

The corrected level of significance was $p<.005$ for 12 of the 16 chisquared values, $p<.01$ for two more of the chi-squared values, and $p$ $<.025$ for the remaining two values. Each of the 16 NDE Scale items therefore differentiated the NDErs from the nonNDErs at a significant level, even with the rigorous Bonferroni correction.

\section{Number and Types of NDEs Described} by NDErs and NonNDErs

Of the 183 respondents who claimed to have had NDEs, 169 (92\%) described experiences that scored 7 or higher on the NDE Scale, while 
Table 1

Percent of NDErs and nonNDErs who endorsed NDE Scale item responses

\begin{tabular}{lccc}
\hline NDE Scale item & $\begin{array}{c}\text { NDErs } \\
(n=183)\end{array}$ & $\begin{array}{c}\text { nonNDErs } \\
(n=63)\end{array}$ & $\begin{array}{c}\text { chi-squared } \\
(d f=2)\end{array}$ \\
\hline $\begin{array}{l}\text { Did time seem to speed up? } \\
\text { 1. No. }\end{array}$ & $16 \%$ & $62 \%$ & $51.29^{* * *}$ \\
$\begin{array}{l}\text { 2. Time seemed to go faster } \\
\text { than usual, or slower. }\end{array}$ & $10 \%$ & $11 \%$ & \\
3. Everything seemed to be & & & \\
$\quad \begin{array}{l}\text { happening all at once; or } \\
\text { time stopped, or lost all }\end{array}$ & & & \\
$\quad$ meaning. & $74 \%$ & $27 \%$ & \\
$\begin{array}{l}\text { Were your thoughts speeded } \\
\text { up? }\end{array}$ & & & \\
1. No. & & & $15.06^{* *}$ \\
2. Faster than usual. & $58 \%$ & $84 \%$ & \\
3. Incredibly fast. & $16 \%$ & $10 \%$ & \\
\end{tabular}

Did scenes from your past come back to you?

1. No.

2. Remembered many past events.

3. Past flashed before me, out of my control.

$75 \%$

$15.27 * *$

$97 \%$

$8 \% \quad 3 \%$

$17 \%$

$0 \%$

Did you suddenly seem to understand everything?

1. No.

$46 \%$

2. About myself or others.

$19 \%$

$35 \%$

$30.28^{* * *}$

3. About the universe.

Did you have a feeling of peace or pleasantness?

1. No.

$8 \%$

$55 \%$

2. Relief or calmness.

$18 \%$

$29 \%$

3. Incredible peace or pleasantness.

$74 \%$

$16 \%$

Did you have a feeling of joy?

1. No.

$23 \%$

$86 \%$

$6 \%$

$8 \%$

2. Happiness.

$20 \%$

$83.48 * * *$

$54.44 * * *$ 


\begin{tabular}{lccc}
\hline NDErs & nonNDErs & chi-squared \\
NDE Scale item & $(n=183)$ & $(n=63)$ & $(d f=2)$ \\
\hline
\end{tabular}

3. Incredible joy.

$57 \%$

$11 \%$

Did you feel a sense of harmony or unity with the universe?

1. No.

2. No longer in conflict with nature.

3. United, one with the world.

$22 \% \quad 73 \%$

$23 \% \quad 10 \%$

$55 \% \quad 17 \%$

Did you see or feel surrounded by a brilliant light?

1. No.

$28 \%$

$87.57^{* * *}$

2. Unusually bright light.

3. Light clearly of mystical or otherworldly origin.

$26 \%$

$94 \%$

$6 \%$

$46 \%$

$0 \%$

Were your senses ore vivid than usual?

1. No.

$34 \%$

$52.64 * * *$

2. More so than usual.

$26 \%$

$70 \%$

3. Incredibly more so.

$40 \%$

$17 \%$

$13 \%$

Did you seem to be aware of things going on elsewhere, as if by ESP?

1. No.

$66 \%$

$88 \%$

2. Yes, but facts not yet corroborated.

$20 \%$

$10 \%$

3. Yes, and facts later corroborated.

$14 \%$

$2 \%$

Did scenes from the future come to you?

1. No.

2. From personal future.

$80 \%$

$9 \%$

3. From the world's future.

$11 \%$

13.43*

$25.38 * * *$

Did you feel separated from your physical body?

1. No.

$14 \%$

$101.72^{* * *}$

$83 \%$ 
Table 1 (cont.)

Percent of NDErs and nonNDErs who endorsed NDE Scale item responses

\begin{tabular}{lccc} 
NDE Scale item & $\begin{array}{c}\text { NDErs } \\
(n=183)\end{array}$ & $\begin{array}{c}\text { nonNDErs } \\
(n=63)\end{array}$ & $\begin{array}{c}\text { chi-squared } \\
(\mathrm{df}=2)\end{array}$ \\
\hline $\begin{array}{l}\text { 2. Lost awareness of body. } \\
\text { 3. Clearly left the body and } \\
\text { existed outside it. }\end{array}$ & $31 \%$ & $14 \%$ & \\
& $55 \%$ & $3 \%$ &
\end{tabular}

Did you seem to enter some other, unearthly world?

1. No.

2. Unfamiliar, strange place.

3. Clearly mystical or unearthly realm.

Did you seem to encounter a mystical presence or being?

1. No.

2. Unidentifiable voice.

3. Definite being, or voice clearly of mystical or otherworldly origin.

$24 \%$

$86.03^{* * *}$

$20 \% \quad 10 \%$

$56 \% \quad 2 \%$

Did you see deceased spirits or religious figures?

1. No.

$64 \%$

$41 \% \quad 95 \%$

$9 \%$

$3 \%$

$50 \%$

$2 \%$

2. Sensed their presence.

3. Saw them.

$11 \%$

$25 \%$

$94 \%$

$6 \%$

$0 \%$

Did you come to a border or point of no return?

1. No.

2. Conscious decision to "return" to life.

3. Barrier I was not permitted to cross; or "sent back" to life involuntarily.

$* \mathrm{p} \leq .0015$; with Bonferroni correction, p. $<.025$ 
14 (8\%) described experiences that fell below the research criterion of 7 for the definition of an NDE. Of the 63 respondents who denied having had NDEs during their close brushes with death, $18(29 \%)$ nevertheless described experiences that scored 7 or higher on the NDE Scale despite their denials, while 45 (71\%) described experiences that fell below the research criterion of 7 for the definition of an NDE. This difference between the two groups was significant at $p<.0001$ (chi-squared $=$ 104.57; $\mathrm{df}=1$ ).

Among the 183 self-described NDErs, 61 (33\%) described experiences that were classified as Cognitive NDEs, $42(23 \%)$ described Affective NDEs, 5 (3\%) described Paranormal NDEs, 43 (24\%) described Transcendental NDEs, and the remaining $32(18 \%)$ described experiences that did not meet criteria for any of those classifications. Among the 63 self-described nonNDErs, $1(2 \%)$ described an experience that was classified as a Cognitive NDE, 8 (13\%) described Affective NDEs, 1 (2\%) described a Paranormal NDE, none described a Transcendental $\mathrm{NDE}$, and the remaining 53 (84\%) described experiences that did not meet criteria for any of those classifications. The difference in distribution of NDE types among self-described NDErs and self-described nonNDErs was significant at $p<.0001$ (chi-squared $=96.45 ; \mathrm{df}=4$ ).

\section{Discussion}

Since subjects in this study volunteered from the ranks of an organization dedicated to near-death research, it may be presumed that they had greater interest in and knowledge of NDEs than would the general population. While there is some evidence that knowledge of NDEs does not influence reports of personal experiences (Greyson and Stevenson, 1980 ), it would be worthwhile to repeat this study with a random sample of individuals who have come close to death.

Regardless of how representative these subjects are of near-death survivors in general, the group of self-described NDErs and the group of self-described nonNDErs were indistinguishable in terms of gender, age at the time of the near-death event, or years elapsed since the neardeath event. These data support previous findings that NDE reports are not associated with gender, age, or elapsed time since the neardeath event (Ring, 1980, 1984; Greyson, 1983, 1986).

The mean NDE Scale score of 16.48 (S.D. $=6.96$ ) for NDErs in the present study is slightly higher than the mean score of 15.01 (S.D. $=$ 7.84) for the sample of NDErs on which the scale was originally tested (Greyson, 1983). This difference is attributable to the new wording of 
the response options to the question about time distortion, which was expected to elicit more positive responses than the original wording. Accordingly, NDErs in the present study scored higher on the Cognitive Component, which includes time distortion, (mean $=3.59$ ) than did NDErs in the original study (mean $=2.35$ ); whereas their mean scores on the other three components were almost identical to those of the original sample of NDErs (Greyson, 1983). Likewise, percentages of NDErs choosing each of the three response options to NDE Scale items are very close to those reported from the original description of the scale (Greyson, 1983) for all individual items except time distortion.

Percentages of positive responses to all 16 items on the NDE Scale, as well as scores on the total scale and the four component subscales, were much higher for the NDErs in this study than for the nonNDErs. Even with the Bonferroni correction for multiple simultaneous statistical tests, every comparison between the two groups reached statistical significance. Nevertheless, it is notable that over a quarter of the nonNDErs gave at least a mildly positive response to questions about time distortion; feelings of peace, joy, and cosmic unity; and unusually vivid senses during their close brushes with death. Those items might therefore be regarded not as features unique to the NDE but as less specific responses to a near-death encounter.

An alternative interpretation of the presence of those NDE features in self-described nonNDErs is that some of those "nonNDErs" did in fact have NDEs, despite their denials. Over a quarter of these respondents who denied having had NDEs did indeed describe experiences that scored 7 or higher on the NDE Scale, meeting the research criterion for an NDE. Why those subjects chose not to regard their experiences as NDEs, and how their experiences compared with those of the subjects who did claim to have had NDEs, are intriguing questions that deserve further study.

Conversely, a few respondents who claimed to have had NDEs described experiences that scored lower than 7 on the NDE Scale, not meeting the research criterion for an NDE. Though they accounted for only eight percent of the self-described NDErs, their reasons for regarding their experiences as NDEs deserve further study, as does a phenomenological comparison of their experiences with those of respondents who did not claim to have had NDEs.

Roughly one third of the experiences reported by NDErs met criteria for Cognitive NDEs, and roughly one quarter each met criteria for Affective and Transcendental NDEs. This represents a somewhat higher proportion of Cognitive NDEs than reported previously (Grey- 
son, 1985); that difference may be attributable to the rewording of the time distortion item, which, as noted above, increased scores on the Cognitive Component. A small number of experiences in the present sample could be classified as Paranormal NDEs, a type not found in the earlier study of NDE typology (Greyson, 1985); and 18 percent of NDErs' experiences could not be classified as to type.

It should be noted that it is possible for an experience to score 7 or higher on the total NDE Scale, qualifying as an NDE, and yet score less than 5 on any given component. Conversely, it is also possible, though rare, for an experience to score less than 7 on the total scale, not qualifying as an NDE, and yet still score 5 or 6 on a single component.

Only 10 of the 63 nonNDErs reported experiences that could be classified as a particular type of NDE, and 8 of those were categorized as Affective NDEs. As noted above, feelings of peace, joy, and cosmic unity-elements of the Affective Component-were reported not uncommonly by nonNDErs. Further research is warranted into whether these affective elements are indeed diagnostic of NDEs or whether they are nonspecific responses to a close brush with death. The respondents themselves were less likely to identify affective experiences as NDEs than they were to identify cognitive or transcendental experiences as NDEs.

\section{References}

Greyson, B. (1983). The Near-Death Experience Scale: Construction, reliability, and validity. Journal of Nervous and Mental Disease, 171, 369-375.

Greyson, B. (1985). A typology of near-death experiences. American Journal of Psychiatry, 142, 967-969.

Greyson, B. (1986). Incidence of near-death experiences following attempted suicide. Suicide and Life-Threatening Behavior, 16, 40-45.

Greyson, B., and Flynn, C. P. (eds.) (1984). The Near-Death Experience: Problems, Prospects, Perspectives. Springfield, IL: Thomas.

Greyson, B., and Stevenson, I. (1980). The phenomenology of near-death experiences. American Journal of Psychiatry, 137, 1193-1196.

Grove, W. M., and Andreasen, N. C. (1982). Simultaneous tests of many hypotheses in exploratory research. Journal of Nervous and Mental Disease, 170, 3-8.

Lundahl, C. R. (ed.) (1982). A Collection of Near-Death Research Readings. Chicago, IL: Nelson-Hall.

Ring, K. (1980). Life at Death: A Scientific Investigation of the Near-Death Experience. New York, NY: Coward, McCann and Geoghegan.

Ring, K. (1984). Heading Toward Omega: In Search of the Meaning of the Near-Death Experience. New York, NY: Morrow.

Rogo, D. S. (1989). The Return From Silence: A Study of Near-Death Experiences. Wellingborough, England: Aquarian Press. 